\title{
Variações paramétricas em pré-requisitos da linguagem: Estudo longitudinal das interações criança-acompanhante
}

\author{
Carlos Barbosa Alves de Souza \\ Sirleany de Souza Pontes \\ Universidade Federal do Pará
}

\begin{abstract}
RESUMO
Este estudo visou identificar em situações naturais de interação criança-acompanhante algumas das variáveis apontadas pelos estudos experimentais como pré-requisitos no processo de aquisição da linguagem (freqüência, tipicidade, contigüidade temporal e direção do olhar na relação palavrareferente), e analisar suas variações paramétricas. Participaram do estudo três crianças (uma menina e dois meninos, todos com dois meses no início do estudo), acompanhadas geralmente por suas mães. As díades foram filmadas uma vez por semana em suas casas, por aproximadamente 15 minutos (a menina até os 7 meses e os meninos até os 5 meses). Os resultados mostraram que: 1) os acompanhantes nomearam diversos objetos e ações, nomeando até os seis meses de idade mais objetos que eventos, e depois mais ações; 2) cada referente foi nomeado principalmente com uma palavra; 3) o acompanhante nomeou basicamente objetos/ações presentes no ambiente imediato da criança; e 4) para duas díades, inicialmente (2 a 5 meses), era principalmente o acompanhante que olhava para o objeto/ação nomeado, mas gradualmente a criança também começa a olhar o referente nomeado. Estes resultados mostram, em uma situação de observação natural longitudinal, a ocorrência de condições que têm sido apontadas como importantes para a aquisição de repertórios lingüísticos.
\end{abstract}

Palavras-chave: pré-requisitos da linguagem; variações paramétricas; interação criança-acompanhante.

\section{ABSTRACT \\ Parametric variations in language prerequisites: A longitudinal study of the infant-caregiver interactions}

This study aimed to identify in infant-caregiver interactions, in natural settings, the occurrence of some variables indicated by experimental studies as language prerequisites (frequency, tipicity, temporal contiguity and direction of gaze in word-referent relation) and to analyze its parametric variations. Two boys and one girl participated, all two months of age at the start of the study, usually accompanied by their mothers. Dyads interactions were recorded at home, one day per week for approximately 15 minutes (the girl until the age of 7 months and the boys until 5 months). Results showed that 1) caregivers named various objects and actions, more objects than events up to six months of age and then more actions; 2) each referent was named mainly with a word 3) basically, caregivers named objects/actions present in the immediate environment and, 4) for two dyads, initially (2 to 5 months), it was especially the caregiver who would look at the named object/action, but gradually the child would also start directing her gaze toward the named referent. Overall, results show, in a naturalistic, longitudinal context, the occurrence of conditions that have been pointed out as important to acquisition of linguistic repertoires.

Keywords: language prerequisites; parametric variations; infant-caregiver interaction.

Historicamente, a aquisição da linguagem vem sendo estudada a partir de duas perspectivas gerais: as correntes estruturalista e funcionalista. A primeira enfatiza a importância dos aspectos formais da linguagem (e.g., fonologia, sintaxe, morfologia, etc.). Já as propostas caracterizadas como funcionalistas referem-se particularmente à ênfase na importância das interações do indivíduo com o seu meio (aspectos pragmáticos) na aquisição da linguagem (ver Souza, 2001, 2003).

A concepção estruturalista apresenta diversos problemas na sua interpretação e análise dos fenômenos lingüísticos (Souza, 2001). Para os adeptos dessa corrente, a linguagem seria, em suma, produto da atividade cognitiva/biológica dos indivíduos. Esta concepção subestima a função exercida pelo ambiente sobre 
o processo de aquisição e desenvolvimento lingüístico (sendo esta a principal limitação do modelo estruturalista), ao passo que, para os funcionalistas, a produção da linguagem estaria situada no âmbito da relação do indivíduo com o meio (Skinner, 1992/1957; Souza, 2001). Desde modo, nos últimos tempos a análise dos aspectos funcionais da aquisição e do desenvolvimento da linguagem vem se constituindo como uma alternativa às tradicionais abordagens estruturais da linguagem (Brino \& Souza, 2005; Ribes \& Quintana, 2003; Souza, 2001, 2003; Tomasello, 2003).

Souza $(2001,2003)$ vem desenvolvendo uma proposta de análise funcional da aquisição e do desenvolvimento lingüístico que parte da noção de 'jogos de linguagem' de Wittgenstein (1953): aprender uma linguagem é aprender diferentes jogos de linguagem, i.e., é aprender a usar o léxico de um idioma em contextos. Com base nesta idéia tem sido sugerido que aprender uma linguagem implica a aquisição de diferentes competências lingüísticas (Moerk, 1996; Souza, 2003). A partir desta concepção, procurou-se estabelecer uma análise funcional desta atividade; ou seja, tratou-se de estabelecer uma análise que especificasse os comportamentos de um falante competente, de um aprendiz/escuta e os contextos (organização espaçotemporal dos estímulos ambientais) onde estes ocorrem, verificando as relações que se estabelecem entre comportamentos e entre estes e os contextos (Souza, 2001).

Souza (2001), com o objetivo de verificar se o simples pareamento entre palavras e objetos era condição suficiente para a aquisição de três competências lingüísticas básicas (1-repetir vocalizações de maneira exata, reduzida, ampliada ou combinada; 2- apontar sob critérios lingüísticos; e 3- designar/denominar objetos/eventos do mundo), iniciou uma série de estudos com crianças de dois anos de idade. Verificou-se que o pareamento palavra-objeto foi condição suficiente para a aquisição das respostas de apontar e denominar (repetir vocalizações já era uma classe generalizada de resposta para todos os participantes do estudo).

Com a finalidade de tornar mais clara a interpretação acerca da aquisição daquelas competências, Souza (2003) realizou um estudo longitudinal com crianças mais novas e verificou que o emparelhamento palavra-objeto não foi condição suficiente para o aprendizado das competências de apontar (em crianças durante o período do $7^{\circ}$ ao $10^{\circ}$ mês) e nomear (do $10^{\circ}$ ao $13^{\circ}$ mês). No entanto, observou-se a aquisição gradual de respostas de observação conjunta, de imitação motora e de imitação vocal, repertórios apontados como pré-requisitos na aquisição da linguagem (Tomasello, 2003). Com base nestes resultados e nos do estudo anterior (Souza, 2001) foi sugerido a importância de certos processos e procedimentos prérequisitos (e.g., pareamentos palavras-objetos) na aquisição da linguagem, enfatizando-se o papel das variações paramétricas no estabelecimento destes prérequisitos.

Whitehurst e colaboradores têm realizado estudos sistemáticos acerca dos efeitos de variações paramétricas em algumas variáveis apontadas como importantes no processo de aquisição da linguagem (e.g., Whitehurst, 1996; Whitehurst \& DeBaryshe, 1989; Whitehurst \& Valdez-Menchaca, 1988). Por exemplo, Whitehurst \& Valdez-Menchaca (1988), indicaram que contingências de reforço (exemplo de relação funcional) são necessárias para que ocorra a produção de nomes (não sendo, no entanto, condição necessária no processo de aquisição de respostas de compreensão). Segundo estes autores, a ação específica destas contingências seria modulada pelas variações paramétricas em algumas varáveis específicas: 1) contigüidade temporal (tempo decorrente entre a nomeação do objeto pelo falante competente e o ver pelo observador); 2) informatividade (grau em que a palavra proferida pelo falante remete ao objeto nomeado); 3) valor do referente (grau de preferência por um referente, quando, diante de uma série de outros objetos, o observador optou por ele); 4) tipicidade (grau em que uma palavra, e não outra, no discurso do falante, desempenha a função de nome do objeto para o observador); 5) relação entre a direção da atenção (direção do olhar) da criança e a nomeação pelo falante; 6) nível de abstração do nome proferido; grau de contexto intraverbal (grau de correlação entre grupos lingüísticos ou entre frases) e 7) freqüência (número de vezes em que a relação entre palavra e referente é apresentada ao observador).

Nos estudos de Whitehurst e cols. que investigaram acerca da contigüidade temporal (ver Whitehurst, 1996), crianças de 2 anos de idade foram expostas a três condições distintas de apresentação de objetos. Na condição presente, cinco objetos novos eram nomeados para a criança no ato da apresentação pelo adulto. $\mathrm{Na}$ condição passada, eram proferidos os nomes de cinco outros objetos novos 10 segundos após a apresentação do objeto. Na condição futura, eram proferidos os nomes de cinco outros objetos novos $10 \mathrm{~s}$. antes da apresentação do objeto. Os resultados obtidos mostraram que o desempenho deu-se de maneira mais 
eficaz na condição presente, com aumento sensível na nomeação receptiva ao longo de todo o experimento (Whitehurst \& Kedesdy, 1981).

Whitehurst e Kedesdy (1981) descrevem um experimento no qual a informatividade entre palavra e referente foi manipulada através da variação da correlação entre palavras e objetos em três condições distintas. Na correlação perfeita, cinco palavras e cinco objetos eram pareados enquanto nas demais condições (as de correlação imperfeita) uma palavra ou um objeto extra funcionava diluindo a correlação (a palavra extra ou o objeto extra era pareada (o) mais de uma vez, alterando a correlação palavra-objeto). Os resultados mostraram que nas condições de correlação imperfeita a aquisição do léxico deu-se de forma retardada quando comparada à situação de correlação perfeita.

Segundo Whitehurst e Kedesdy (1981) a aprendizagem da relação existente entre dois eventos depende das características desses eventos e de que "sentido" elas têm para o aprendiz. Este é o argumento que reforça a importância do valor do referente como uma variável relevante no processo lingüístico. O experimento conduzido pelos autores acerca dessa variável consistiu na aplicação de um pré-teste constituído de um componente de produção e outro de compreensão para verificar se as relações que seriam posteriormente treinadas já integravam o repertório da criança; um treino de relações entre palavras e referentes e um pós-teste, o qual tinha a função de verificar se as relações eram aprendidas. Foram realizadas três sessões de treino e pós-teste de produção e compreensão, idêntico ao pré-teste. Os resultados mostraram que as crianças tenderam a aprender os nomes dos objetos que elas mais valorizavam. Houve uma forte correlação positiva entre o valor atribuído a determinado referente e a rapidez com que este era associado ao nome correspondente.

Whitehurst, Kedesdy e White (1982) realizaram uma outra série de experimentos sobre a tipicidade do objeto nomeado. Um deles, com crianças pré-escolares, envolveu a nomeação de membros típicos de uma categoria, a qual deveria ser coerente com as práticas de nomeação da mãe. Em uma condição de nomeação-simples, cada instância de uma categoria (seis ao todo) foi apresentada sozinha, sem referência a nenhum contexto. Na condição de nomeação contextual, duas imagens de algumas categorias eram apresentadas e o experimentador descrevia o contexto de uma situação imaginária e relacionava-o a cada imagem. As mães eram instruídas a incluir em sua fala para a criança a apresentação de um par típico (palavra-referente), um atípico e um misto por cada uma das seis categorias. Os resultados mostraram que a nomeação simples não produziu a aprendizagem da relação entre palavra e referente, enquanto que os resultados da nomeação típica foram superiores aos da nomeação de eventos atípicos.

Em sua maioria, os termos iniciais de referência da criança são aprendidos no contexto que Roger Brown (1958, citado em Whitehurst \& Kedesdy, 1981) denominou "jogo original de palavras", no qual um tutor (falante competente) nomeia coisas em circunstâncias geralmente cotidianas à criança, que aprende, ao longo do jogo, algumas dessas relações. A aprendizagem da relação entre palavras e coisas é confirmada quando as próprias tentativas da criança de manipular a relação produzem acerto (Whitehurst \& Kedesdy, 1981).

Segundo Whitehurst e colaboradores, a aquisição da relação palavra-referente, ocorrida na relação entre tutor e aprendiz é produto da conclusão da aprendizagem observacional, na qual aspectos do contexto influenciam o comportamento do observador em suas dimensões correspondentes. No caso da aquisição do léxico, a resposta modelada é o próprio nome (ou palavra) e o contexto no qual este é imitado, compreendido ou produzido é o referente (Whitehurst \& Kedesdy, 1981).

A partir dos dados obtidos por Souza (2001, 2003) e por Whitehurst e cols. (e.g., Whitehurst, 1996), esse estudo visou 1) identificar nas situações de interação criança-acompanhante em situações naturais (durante o primeiro ano de vida da criança), algumas das variáveis apontadas pelos estudos experimentais como importantes no processo de aquisição da linguagem (e.g., "Freqüência" e "Tipicidade" da relação palavra/referente, contigüidade temporal entre escutar o nome de um objeto e o ver - "Índice de Contexto" - e "Direção do Olhar" para o referente); e 2) analisar suas variações paramétricas.

\section{MÉTODO}

Participantes: Participaram três crianças (dois meninos e uma menina), todas com dois meses de idade no início do estudo, sem problemas de saúde, filhos únicos de famílias de classe média, tendo como principal acompanhante a própria mãe. Os responsáveis pelas crianças assinaram um termo de consentimento livre e esclarecido (conforme os critérios estabeleci- 
dos na resolução 196/96 do Conselho Nacional de Saúde), autorizando o desenvolvimento do estudo.

Equipamento: Foi utilizada uma câmara de vídeo (8 $\mathrm{mm}$ ), um tripé e os brinquedos de cada criança. Estes foram de diferentes tipos (bichos de pelúcia, bonecas, livros, etc) e variavam a cada sessão de filmagem.

Procedimento de coleta de dados: Foi realizada uma sessão por semana, na residência de cada participante, sem dia fixo. Cada sessão tinha um tempo de duração que dependia do momento de interação criança-acompanhante registrado (uma média de 15 minutos por sessão), o qual poderia ser (a) uma situação de higiene (banho ou troca de fraldas), (b) uma situação na qual a criança estivesse sendo alimentada (através de mamadeira ou seio materno) ou (c) uma situação na qual o acompanhante estivesse brincando com a criança. Deu-se preferência à situação (c), por ser o momento em que a criança mostrava-se mais participativa. No início da sessão, o experimentador ligava a câmara, posicionando-a em um tripé, de modo que registrasse o melhor ângulo frontal da interação, e então iniciava a filmagem, sem interferir nela. Ao término da mesma, desligava a câmara e desmontava o equipamento.

Procedimento de análise dos dados: As gravações foram analisadas em intervalos de 5 minutos. Buscouse identificar em cada momento da interação do adulto com a criança a ocorrência das variáveis mencionadas anteriormente. Considerando os possíveis repertórios da criança nesta etapa do desenvolvimento (2-12 meses), foram estudadas as seguintes variáveis: "Índice de Contexto", relativa à contigüidade temporal nomeobjeto/ação (distribuída em três categorias, CT0 condição presente de nomeação do referente, CT1 condição passada de nomeação do referente e CT2 condição futura de nomeação do referente), "Tipicidade” do objeto nomeado, relação entre a atenção ("Direção do Olhar”) da criança/mãe e a nomeação pelo falante (distribuída em quatro categorias, A olhar do acompanhante para referente nomeado, C olhar da criança para referente nomeado, AC - olhar de ambos para referente nomeado e DF - olhar em diferentes direções) e a "Freqüência" com que o objeto foi nomeado.

Trinta por cento das sessões foram analisadas por dois experimentadores para estabelecer um índice de concordância entre observadores ([Concordâncias/Concordâncias + Discordâncias] x 100) para o registro das categorias analisadas, produzindo uma concordância que variou de 89 a 100\% para as diferentes categorias.

\section{RESULTADOS}

Foram registradas e analisadas 22 sessões de interação criança-acompanhante do Participante 01 (dos 2 meses aos 7), e 17 e 15 sessões, respectivamente, dos Participantes 2 e 3 (dos 2 aos 5 meses aproximadamente). Os resultados da "Freqüência" absoluta da utilização de palavras e respectivos referentes bem como os escores obtidos acerca da variável "Tipicidade" podem ser vistos nas Tabelas 1, 2 e 3. Pode-se observar nestas Tabelas uma freqüência elevada de nomeações por parte do acompanhante de objetos e ações. De maneira geral, verifica-se quanto à "Freqüência" de nomeações que a criança foi o referente mais nomeado, e que mais objetos que ações foram nomeados pelo acompanhante. No entanto, esta relação tende a se inverter a partir do sexto mês de vida da criança, como pode ser visto pelo elevado número de nomeações de ações apresentadas ao Participante 1. No que concerne à variável "Tipicidade", observou-se que o acompanhante raramente utilizava mais de três palavras diferentes para um dado referente (com exceção de nomeações do próprio bebê), utilizando geralmente uma determinada palavra para se referir a certo objeto/evento. 
TABELA 1

Freqüência das Nomeações Emitidas pelo Acompanhante do Participante 01 e seus Respectivos Referentes em 22 Sessões

\begin{tabular}{|c|c|}
\hline Referentes & Nomeações e valores correspondentes \\
\hline Criança & $\begin{array}{l}\text { Nenê (98), meu amor (55), filha (36), bebê (31), "nome do bebê" (29), } \\
\text { bebê da mamãe (23), "diminutivo do nome do bebê" (21), bebezinho (8), chorona (7), } \\
\text { nenê da mamãe (6)... }\end{array}$ \\
\hline Mãe & $\begin{array}{l}\text { Mamãe (55), mama (23), mãe (5), meu amor (1), mamãezinha (1), } \\
\text { Amor (1), "nome da mãe" (1) }\end{array}$ \\
\hline Pai & Papai (20), papa (8), "nome do pai" (4), pai (3), gordo (1) \\
\hline Avó & Vovó (53), avó (15), vó (2) \\
\hline Tia & Tia (8), titia (3) \\
\hline Boca & Boca (4) \\
\hline Mão & Mão (4) \\
\hline Dedo & Dedinho (1) \\
\hline Pé & Pé (11) \\
\hline Dente & Dentinho (2), dente (1) \\
\hline Fralda & Fralda (2) \\
\hline Urso de brinquedo & Ursinho (5), urso (2), bichinho (2), brinquedo (2), ursinho (2), brinquedinho (1) \\
\hline Peixe de brinquedo & Peixinho (3), brinquedo da bebe (2), brinquedo da juju (2), brinquedo (2) \\
\hline Vaca de brinquedo & Vaquinha (7) \\
\hline Chocalho & Chocalho (1) \\
\hline Tambor de brinquedo & Tamborzinho (5), música (1), música (1) \\
\hline Pato de brinquedo & Patinho (7), brinquedinho (1), desenho (1) \\
\hline Boneca & Mônica (4), boneca (1) \\
\hline Bola & Bola (9) \\
\hline Toalha & Toalha (2), toalhinha (2) \\
\hline Revista & Revista (18) \\
\hline Gato & Gatinho (12) \\
\hline Televisão & Televisão (1) \\
\hline $\begin{array}{l}\text { Movimento com as } \\
\text { pernas (bebê) }\end{array}$ & Exercício (2), ginástica (1) \\
\hline Ações & $\begin{array}{l}\text { Olhar (189), pegar (75), sentar (11), ver (11), virar (10), girar (9), conversar (7), cair (7), } \\
\text { brincar (5), beijar (4), bater palmas (3), rir (2), chorar (10), passear (1), morder (1), ensinar (1), } \\
\text { cantar (1), dormir (1), machucar (1), jogar (1), reclamar (1) }\end{array}$ \\
\hline
\end{tabular}

Nota. Alguns referentes que foram nomeados menos de 5 vezes no total não foram apresentados na tabela para não torná-la muito extensa, o mesmo ocorrendo nas Tabelas 2 e 3. 
TABELA 2

Freqüência das Nomeações Emitidas pelo Acompanhante do Participante 02 e seus Respectivos Referentes em 17 Sessões

\begin{tabular}{|c|c|}
\hline Referentes & Nomeações e valores correspondentes \\
\hline Criança & $\begin{array}{l}\text { "Nome do bebê" (66), bebezinho (25), filho (56), bebê (46), bebezão (34), meu amor (31), } \\
\text { "diminutivo do nome da criança" (28), Nenê (20), filhote (11), nenezinho (6), bebê lindo (5). }\end{array}$ \\
\hline Mãe & Mãe (54), mamãe (46) \\
\hline Avó & Avó (4), vó (2), vovó (1) \\
\hline Pai & Pai (1), papai (11) \\
\hline Nádega & Bumbunzinho (7), bunda (5), bumbum (1) \\
\hline Perna & Pernas (6), perninhas (5), pernão (2), pernonas (1) \\
\hline Mão & Mão (29), mãozinha (16) \\
\hline Boca & Boca (13) \\
\hline Fralda & Fralda (7), fraldinha (5) \\
\hline Hipopótamo de brinquedo & Hipopótamo (15), brinquedos (2) \\
\hline Centopéia de brinquedo & Centopéia (15), brinquedos (2) \\
\hline Baleia de brinquedo & Obesa (27) \\
\hline Pato de brinquedo & Pato (9) \\
\hline Bola & Bola (14), bolinha (10) \\
\hline Carro de brinquedo & Carrinho (11) \\
\hline Cão de brinquedo & Cachorrinho (5) \\
\hline Macaco de brinquedo & Macaquinho (10) \\
\hline Porco de brinquedo & Porquinha (5) \\
\hline Câmera de vídeo & Luz vermelha (24), câmera (7), ponto vermelho (2) \\
\hline Bordas da rede & Franjas (18) \\
\hline Coriza do bebê & Queijo (7) \\
\hline Bochecha & Bochechinha (5) \\
\hline Pé do bebê & Pezinho (15), pé (7) \\
\hline Boca do bebê & Boca (8) \\
\hline Mão do bebê & Mão (6), mãozinha (3) \\
\hline Meia & Meia (7) \\
\hline Blusa & Blusinha (6), blusa (2) \\
\hline Lua & Lua (6) \\
\hline Argolas & Argolas (8) \\
\hline Desenho do saci & Saci (11), desenho (5) \\
\hline Desenho doBoto & Boto (13) \\
\hline $\begin{array}{l}\text { Movimentos repetidos com as } \\
\text { pernas do bebê }\end{array}$ & Bicicleta (10), ginástica (1) \\
\hline Ações & $\begin{array}{l}\text { Olhar (145), pegar (35), beijar (22), mostrar (21), tentar (24), ver (11), virar (10), girar (9), puxar (8), } \\
\text { brincar (5), morder (4), levantar (2), dormir (4), falar (1) }\end{array}$ \\
\hline
\end{tabular}


TABELA 3

Freqüência das Nomeações Emitidas pelo Acompanhante do Participante 03 e seus Respectivos Referentes em 15 Sessões

\begin{tabular}{|c|c|}
\hline Referentes & Nomeações e valores correspondentes \\
\hline Criança & $\begin{array}{l}\text { "Coió coió" (64), "nome do bebe" (64), bebê (45), Li (26), lili (29), filho (19), nenê (12), Meu filho (9), } \\
\text { mocinho (8), pretinho da mamãe (5), Moreno (5), pesado (4), palhacinho (4), menininho (3)... }\end{array}$ \\
\hline Mãe & Mamãe (39), mãe (30) \\
\hline Pai & Papai (17), papa (2) \\
\hline Mão da criança & Mãozinha (7), mão (4), mãozinha da mamãe (1) \\
\hline Boca da criança & Boca (30) \\
\hline Dedo da criança & Dedo (10), dedinho (2) \\
\hline Pé da criança & Pezinho de nenê (3) \\
\hline Olho da criança & Olhão (3) \\
\hline Axila do bebê & Suvaco (5) \\
\hline Cabeça da criança & Cabeça (4) \\
\hline Cão & Au au (25), Jony (11), cachorro (10), cachorrinho (3) \\
\hline Cadela & Paloma (8) \\
\hline Pandeiro de brinquedo & Pandeirinho (8), brinquedinho (6), brinquedo (10), música (1) \\
\hline Bola & Bola (3) \\
\hline Pipo & Pepetinha (9), pipo (9) \\
\hline Água & Água (11) \\
\hline Câmera de vídeo & Câmera (7) \\
\hline Talco & Talquinho (2), talco (4) \\
\hline Toalha & Toalha (5) \\
\hline Fralda & Pano (5) \\
\hline Bolacha & Bolacha (2) \\
\hline $\begin{array}{l}\text { Movimentos repetidos } \\
\text { com as pernas do bebe }\end{array}$ & Bicicleta (10) \\
\hline $\begin{array}{l}\text { Movimentos repetidos } \\
\text { no colo da mãe }\end{array}$ & Cavalinho (10) \\
\hline Ações & $\begin{array}{l}\text { Olhar (47), beijar (37), chorar (24), apertar (16), bater (12), virar (11), ir (9), lavar (7), morder (6), } \\
\text { sentar (5), baixar (5), bater (5), andar (4), segurar (3), brincar (3) }\end{array}$ \\
\hline
\end{tabular}

Estão dispostos nas figuras a seguir, sobre a variável "Índice de Contexto", os resultados sobre a freqüência total de cada tipo de contigüidade temporal na apresentação palavra-referente (Figuras 1, 2 e 3) e a freqüência acumulada (em intervalos de 5 minutos, com três intervalos correspondendo aos dados de uma sessão/semana) (Figuras 4, 5 e 6) em todas as sessões analisadas de cada participante. Os escores totais mostraram que a condição presente (CT0) ocorreu com maior freqüência nas nomeações de todos os acompanhantes. Os dados da freqüência acumulada revelaram uma consistência neste padrão, mostrando que a nomeção na CT0 foi utilizada preferencialmente tanto no início das interações (aos 2 meses de vida) como posteriormente (aos 6-7 meses); sendo que neste último período pode-se observar um pequeno aumento na ocorrência de nomeações nas condições passada (CT1), principalmente, e futura (CT2). 


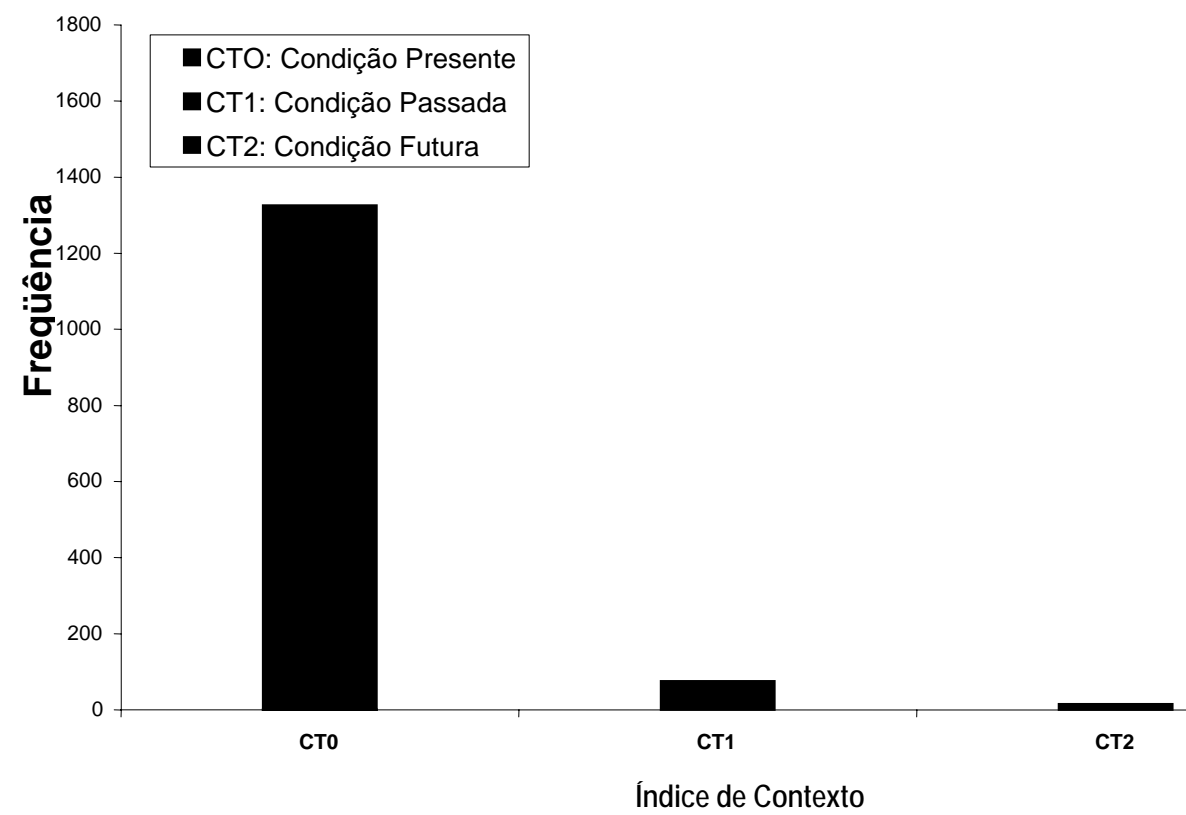

Figura 1. Freqüência do Índice de Contexto nas sessões com o Participante 1.

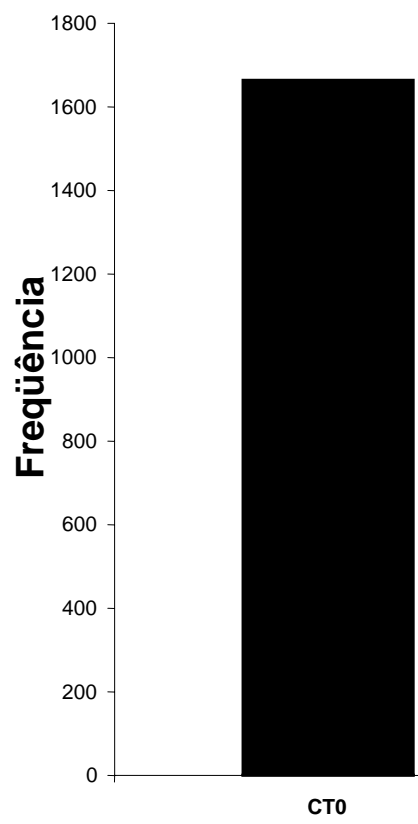

CT0: Condição Presente

- CT1: Condição Passada

- CT2: Condição Futura

Figura 2. Freqüência do Índice de Contexto nas sessões com o Participante 2. 


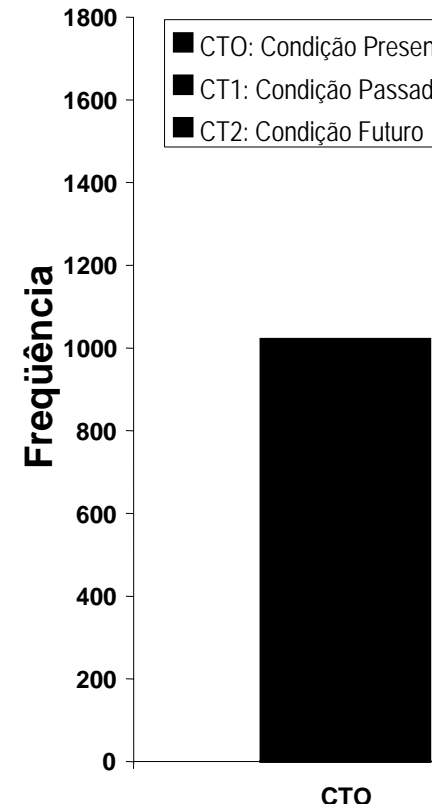

Сто

CT1

CT2

Indice de Contexto

Figura 3. Freqüência do Índice de Contexto nas sessões com o Participante 3.

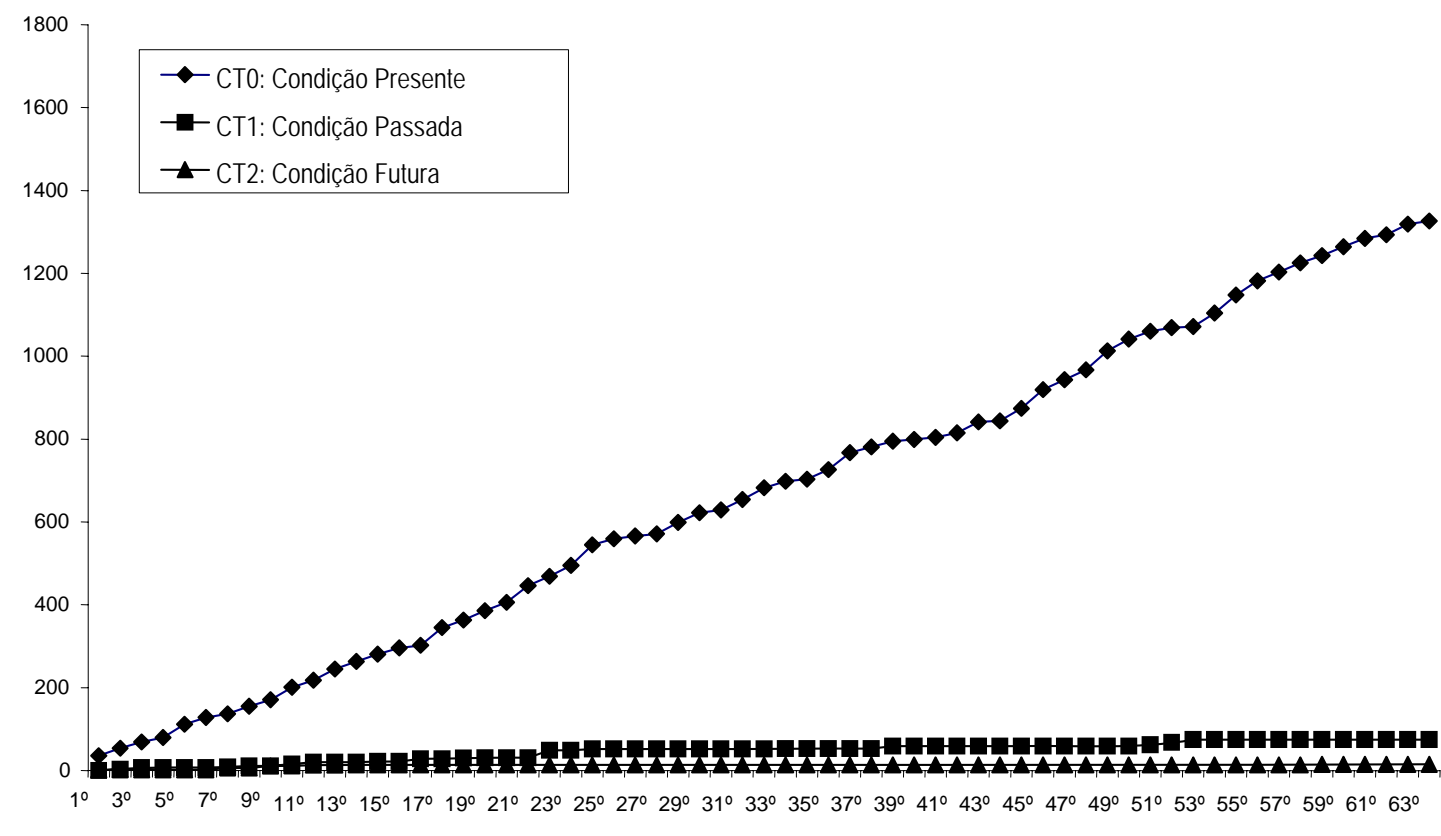

Intervalos

Figura 4. Freqüência acumulada do Índice de Contexto nas sessões com o Participante 1. 


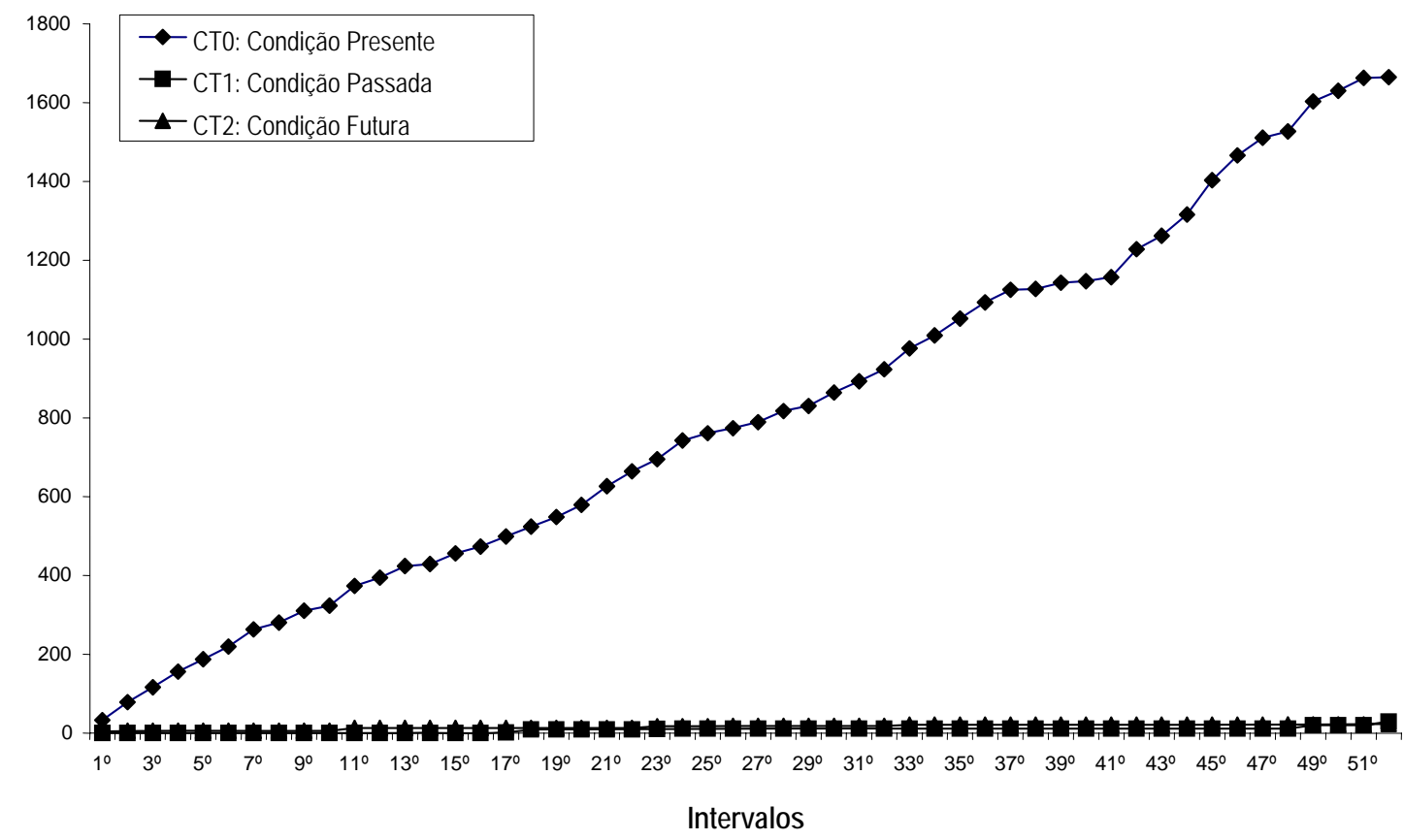

Figura 5. Freqüência acumulada do Índice de Contexto nas sessões com o Participante 2.

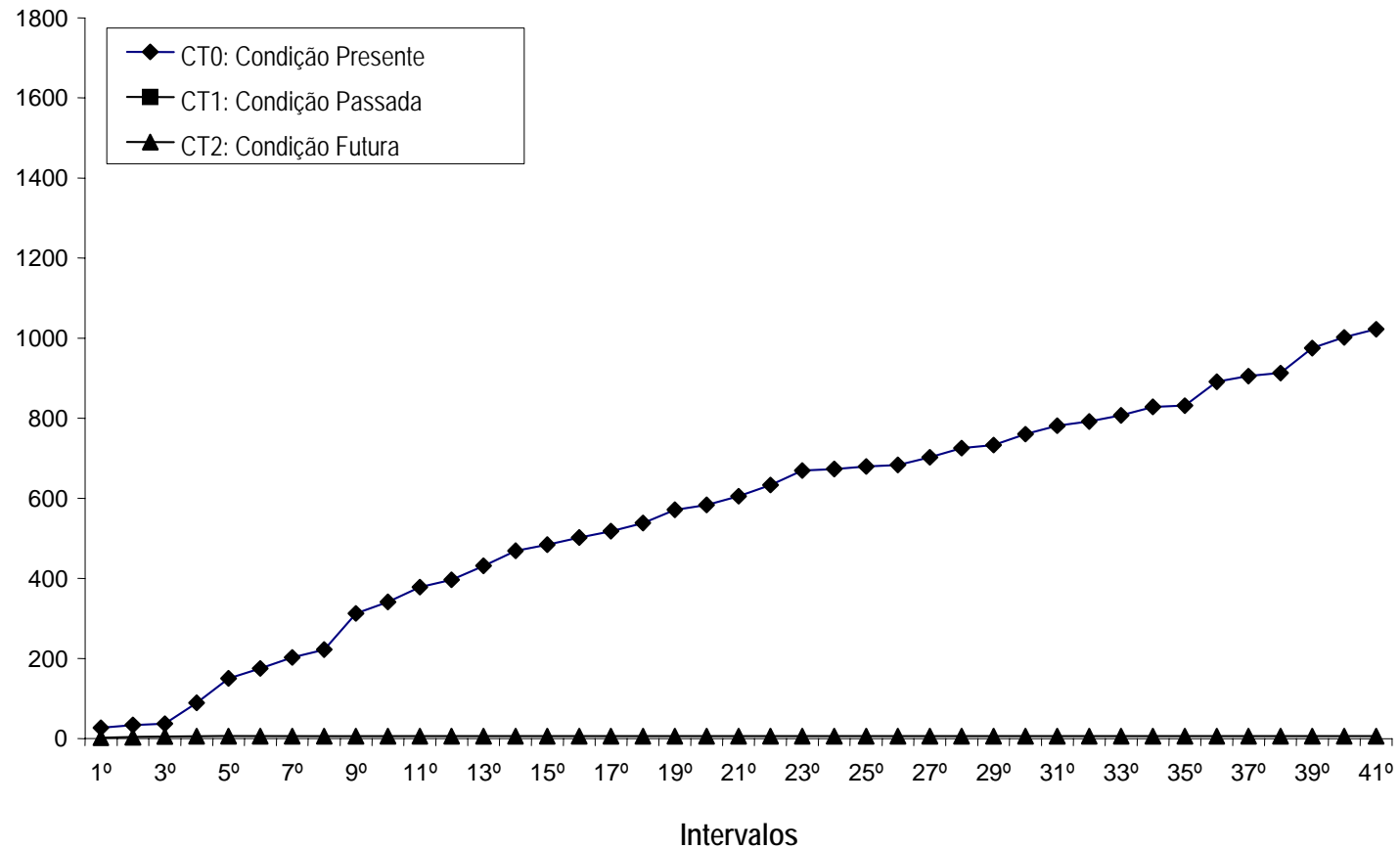

Figura 6. Freqüência acumulada do Índice de Contexto nas sessões com o Participante 3. 
As próximas figuras mostram os escores obtidos sobre a variável "Direção do Olhar". As Figuras 7, 8 e 9 mostram a freqüência total de cada nível da variável tomando todas as sessões dos três participantes, e as Figuras 10, 11 e 12 mostram suas freqüências acumuladas ao longo das sessões. Os resultados da freqüência total mostram que durante as nomeações dos objetos/eventos na maioria das vezes era o acompanhante que olhava para o referente (principalmente para os Participantes 2 e 3). Além disto, verificou-se que no caso do Participante 1 houve também uma alta ocorrência do olhar da criança para o referente, enquanto que para os Participantes 2 e 3 o olhar de ambos (criança e acompanhante) para diferentes referentes foi a categoria de "Direção do Olhar" com a segunda maior freqüência durante as nomeações.

Os resultados da freqüência acumulada da "Direção do Olhar” ao longo das sessões mostram três pa- drões. Um primeiro nas interações da díade do Participantes 1 , nas quais inicialmente se registrou uma maior freqüência do olhar da criança para o referente (C), mas a partir do terceiro mês de vida da criança houve um aumento no olhar do acompanhante para o referente (A), até apresentar uma ocorrência um pouco maior que (C), e um aumento no olhar de ambos para o referente (AC) a partir do sexto mês.

Um segundo padrão foi observado nas interações da díade do Participante 2, ocorrendo inicialmente uma maior freqüência de (A), mas a partir do terceiro mês houve um aumento em (C) e no olhar de ambos para referentes distintos (DF). Um terceiro padrão caracterizou as interações da díade do Participante 3, que foi semelhante ao da díade do Participante 2, mas não se observou aumentos em (C).

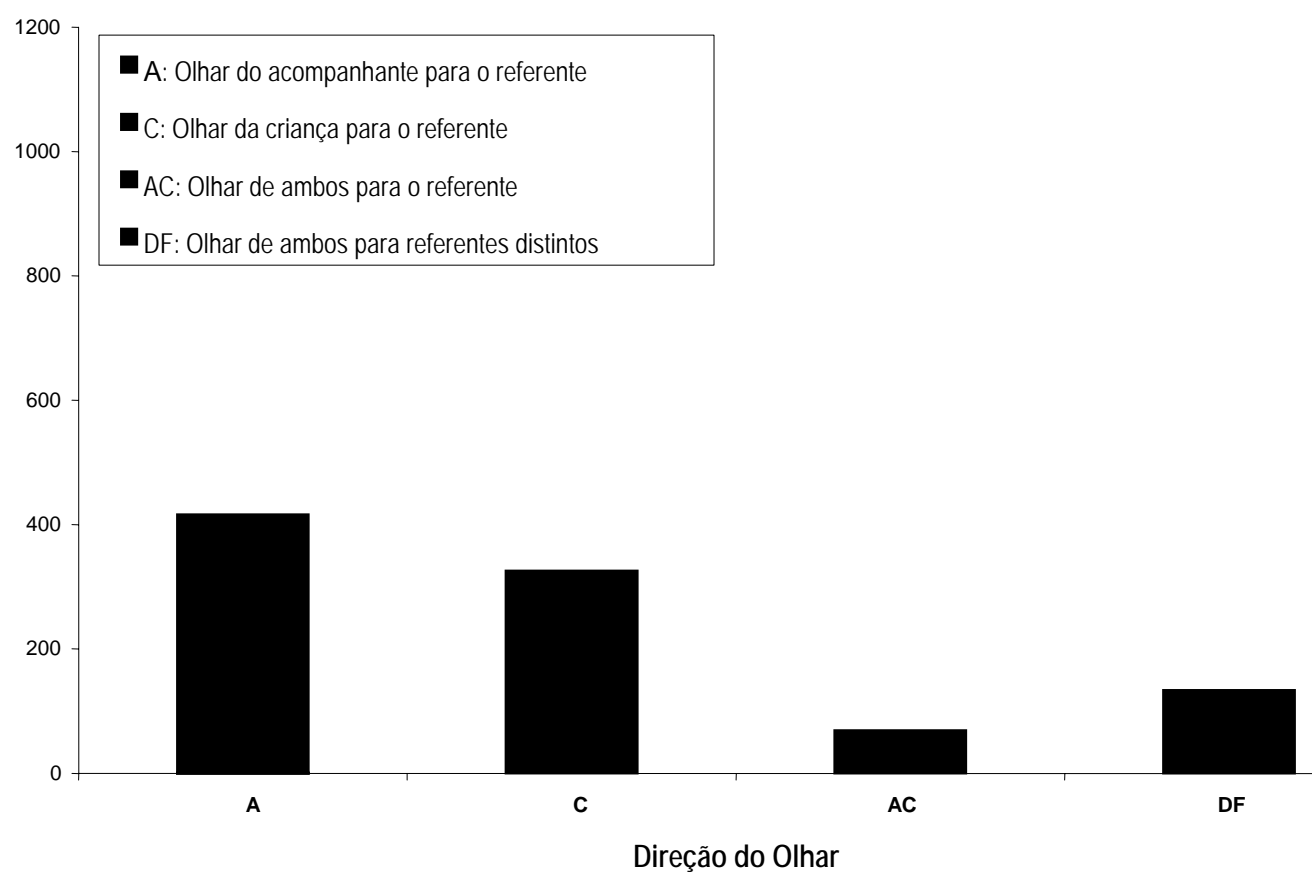

Figura 7. Freqüência da Direcão do Olhar nas sessões com o Participante 1. 


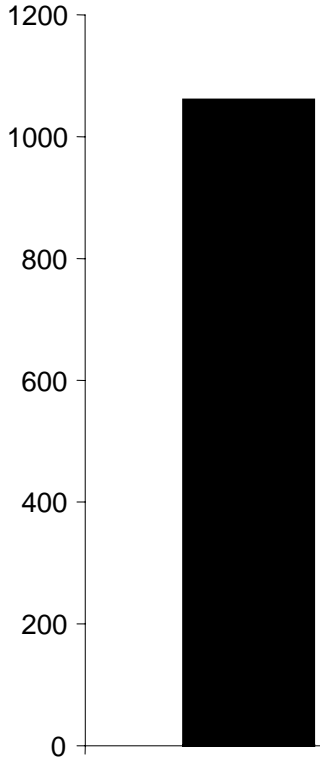

A
A: Olhar do acompanhante para o referente

C: Olhjar da criança para o referente

AC: Olhar de ambos para o referente

DF: olhar ambos para referentes distintos

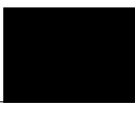

C

\section{Direção do Olhar}

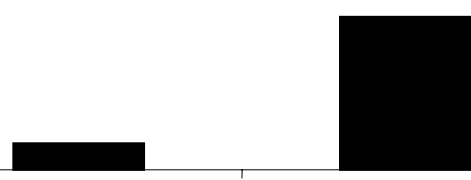

AC

DF

Figura 8. Freqüência da Direcão do Olhar nas sessões com o Participante 2.

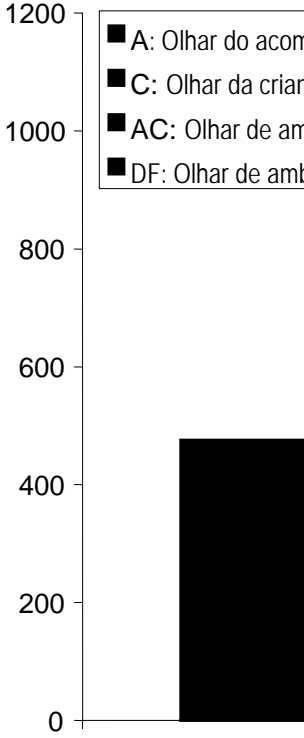

A
C

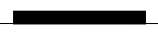

AC

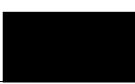

DF

Direção do Olhar

Figura 9. Freqüência da Direcão do Olhar nas sessões com Participante 3. 


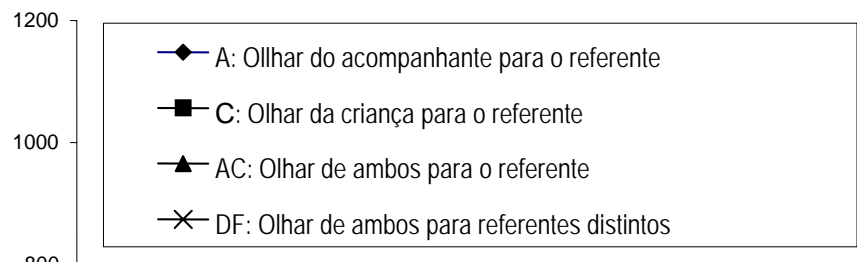

800

600

400

200

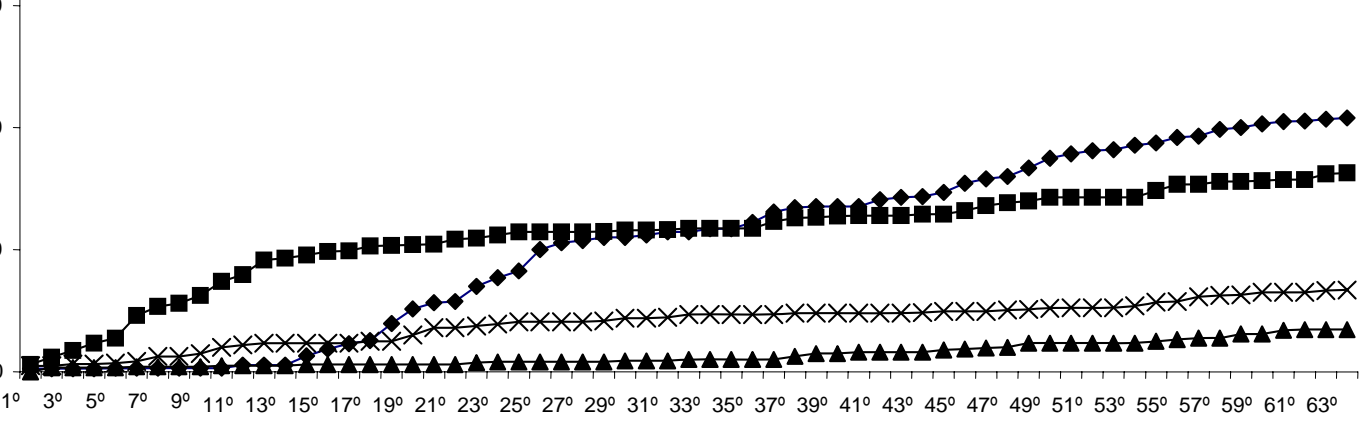

Intervalos

Figura 10. Freqüência acumulada da Direcão do Olhar nas sessões com o Participante 1.

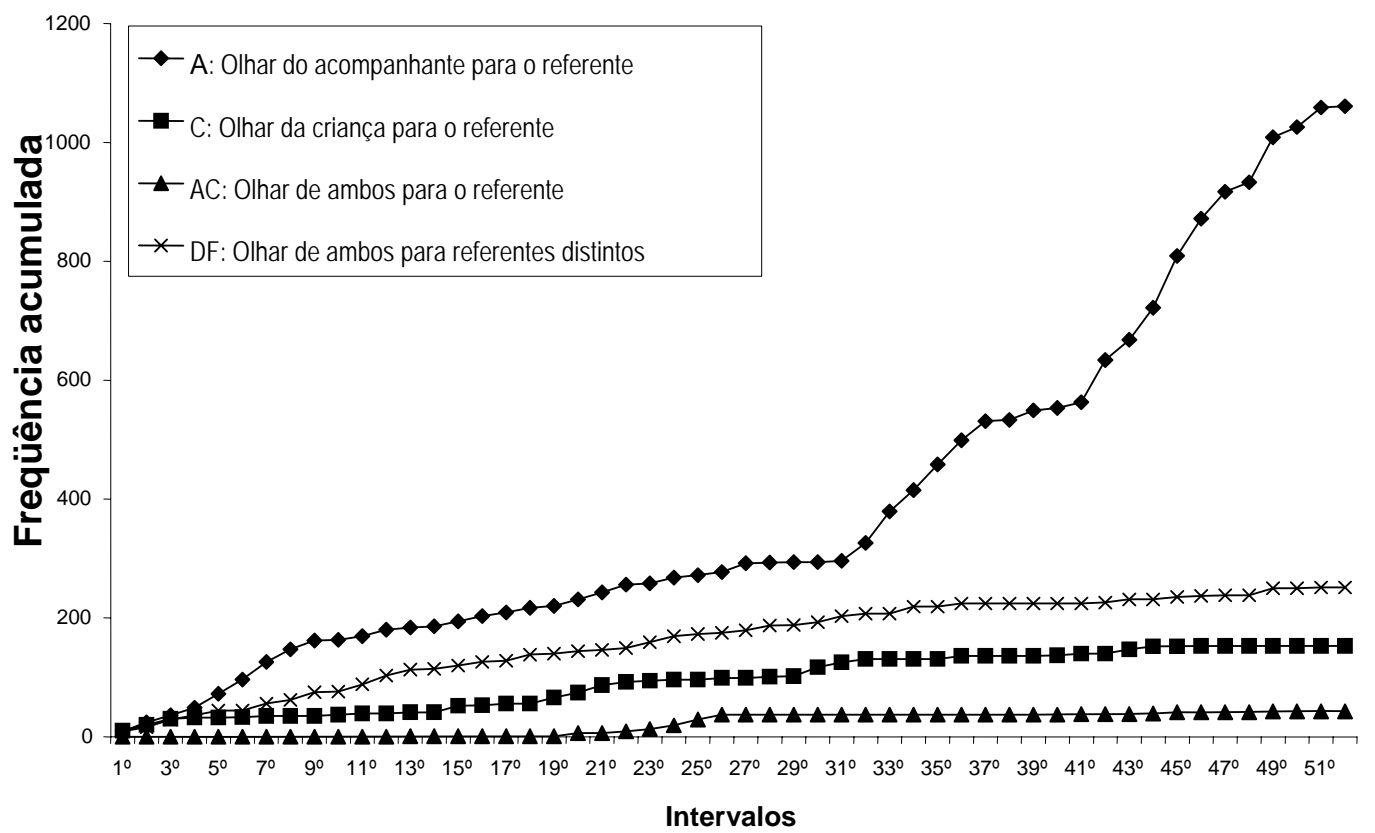

Figura 11. Freqüência acumulada da Direção do Olhar nas sessões com o Participante 2. 


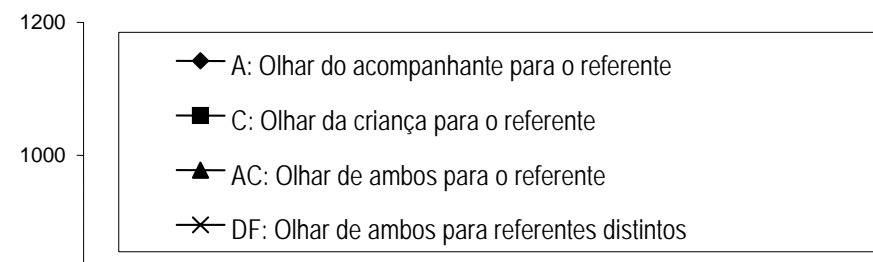

800

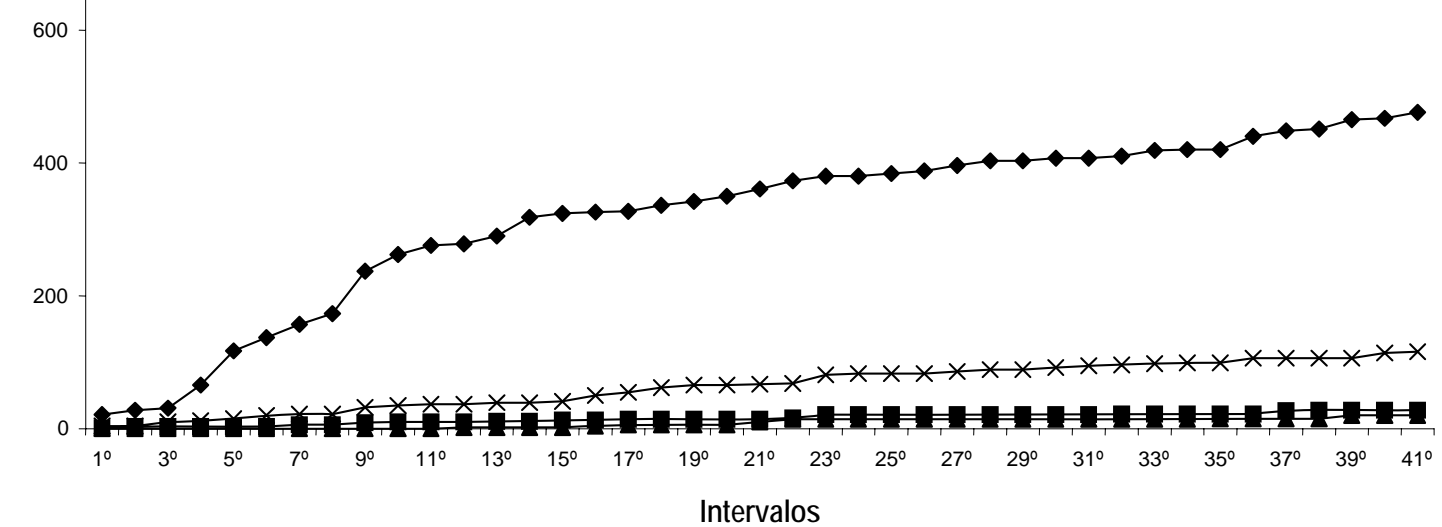

Figura 12. Freqüência acumulada da Direcão do Olhar nas sessões com o Participante 3.

\section{DISCUSSÃO}

Os resultados da freqüência absoluta de utilização de palavras e respectivos referentes (i.e., os dados sobre "Freqüência" e "Tipicidade") revelaram uma elevada ocorrência de nomeações dos objetos/eventos do ambiente imediato da criança, e que certo referente foi nomeado principalmente, quando não exclusivamente, com certa palavra. De forma mais específica se observou um aumento nas nomeações de eventos (ações) a partir do sexto mês de vida da criança. Considerando que este padrão seja representativo das interações destas crianças-acompanhantes no seu dia-adia, pode-se supor que já nesta fase inicial da vida estas crianças estavam sendo expostas a um número elevado de pareamentos palavras-objetos/eventos, com um alto padrão de tipicidade/informatividade na relação palavra-referente, variáveis importantes no processo de aquisição de diferentes competências lingüísticas (Souza, 2003; Whitehurst \& Kedesdy, 1981; Whitehurst e cols., 1982).

Considerando ainda que as palavras sempre ocorriam em frases (e.g., "Olhe a boneca"; dado não demostrado), estes resultados mostram que crianças desta idade podem ser expostas a um grande número de "modelos gramaticais" adequados de certo(s) idioma(s). Este dado contrasta com a "hipótese da pobreza de estímulos”, que sugere que as crianças aprendem um idioma apesar da baixa freqüência de exemplares dos elementos gramaticais aos quais elas são expostas nos primeiros anos de vida (ver Pullum \& Scholz, 2002, para um tratamento crítico desta hipótese). Uma análise que está em andamento, procurando registrar a freqüência de utilização de frases (modelos gramaticais) na interação dos participantes deste estudo (Cavalcante \& Souza, 2006) poderá reforçar os argumentos que têm defendido que a aprendizagem de uma língua passa, em parte, pela exposição repetida a certas estruturas verbais com diferentes elementos (ex. “Olha X”, onde X pode ser “a bola”, “a mão” etc.), o que possibilitaria a emergencia de uma resposta generalizada da criança para outras frases com a mesma estrutura (Stemmer, 1992, 1996; Tomasello, 2003).

Os dados posteriores a idade em comum dos participantes (até os 5 meses) mostraram, conforme mencionado antes, um aumento na nomeação de ações nas interações do Participante 1 com sua acompanhante. Isto parece estar relacionado com 1) o aumento da atividade motora do proprio bebê, a qual é verbalizada seguidamente pela acompanhante durante a interação; e 2) com o aumento e refinamento do comportamento de observação do ambiente por parte da criança, ocasionando maior probabilidade de respostas de observação de ações além daquelas apresentadas direta- 
mente pelo acompanhante, ações essas que também passam a ser verbalizadas pelo acompanhante.

Os resultados sobre a contigüidade temporal ("Índice de Contexto”) das apresentações palavrareferente na interação criança-acompanhante dos três participantes mostraram a preponderância da nomeação do acompanhante de objetos/eventos presentes no ambiente imediato da crianca (CT0- condição presente). Estes dados mostram que os "jogos de linguagem" ocorrem, pelo menos na sua fase inicial, principalmente na condição presente, corroborando os estudos que sugerem a importância desta variável na aquisição dos repertórios pré-verbais e verbais (Whitehurst, 1996; Whitehurst \& Kedesdy, 1981). De acordo com Whitehurst e Kedesdy (1981), 10 segundos que distanciaram a apresentação do objeto e a nomeação pelo falante, prejudicaram significativamente o desempenho lingüístico, atrasando a aprendizagem de respostas de compreensão e produção.

Nos resultados sobre a "Direção do olhar" com relação ao referente nomeado, verificou-se, de maneira geral, uma maior ocorrência do olhar do acompanhante para o referente (A). No entanto, deve-se levar em consideração o fato de que freqüentemente a própria criança era o referente nomeado (pelo menos até os cinco meses de vida). Este dado se ajusta àqueles da literatura sobre a interação mãe-criança, os quais indicam que as mães, inicialmente, passam mais tempo interagindo diretamente com a criança do que apresentando para ela os objetos/eventos do mundo (Lyra, 2000; Seidl de Moura e cols., 2004). Este contato face-a-face, durante as interações nas quais os acompanhantes 'conversam' (fenômeno chamado de motherese) com os bebês, parece favorecer a produção de sons pelo bebê (Correa, 1999; Zamberlan, 2002), o que poderia aumentar a probabilidade de ocorrência deste padrão comportamental na etapa inicial das interações criança-acompanhante.

Por outro lado, os dados sobre a freqüência acumulada da "Direção do Olhar" ao longo das sessões mostraram nas interações da díade do Participante 1 um padrão no qual inicialmente se registrou uma maior freqüência do olhar da criança para o referente (C), e somente a partir do terceiro mês de vida da criança se observa um aumento em (A). Este padrão sugere que no caso desda díade, o acompanhante parecia procurar 'mapear' a direção do olhar da criança e ir ‘apresentando' para ela os objetos/eventos do mundo, em uma outra forma de interagir inicialmente com bebês. $\mathrm{O}$ andamento deste estudo com os participantes estudados aqui e com novos participantes permitirá avaliar 1) se este padrão ocorre com suficiente freqüência para ser efetivamente tomado como um possível tipo de ajuste comportamental nas interações criança-acompanhante; e 2) os seus efeitos no desenvolvimento de repertórios importantes para a aquisição da linguagem, como o comportamento de exploração visual sistemática e de "olhar conjunto” (mutual gazing) (Butterworth \& Grover, 1988; Lowenkron, 1998; Souza, 2003). No caso do Participante 1 do presente estudo, este padrão pelo menos não pareceu prejudicar o desenvolvimento das respostas da criança de olhar para os referentes (C), e de olhar para o mesmo referente que o acompanhante estava olhando (AC).

De modo geral, os resultados deste estudo mostraram, em uma situação de observação natural longitudinal, a ocorrência de condições que têm sido apontadas como importantes para a aquisição de repertórios lingüísticos (Souza, 2003; Tomasello, 2003; Whitehurst, 1996). Tomados juntamente com os resultados de outros estudos que têm procurado verificar o efeito de diferentes processos e procedimentos comportamentais na aquisição destes mesmos repertórios (e.g., Souza \& Affonso, 2007; Vieira, Brasil \& Souza, 2005) eles representam um primeiro avanço na tentativa de estabelecer uma análise estritamente funcional do processo de aquisição e desenvolvimento da linguagem.

Pretende-se dar continuidade a este estudo longitudinal 1) com os mesmos participantes, procurando investigar como a aquisição de certos pré-requisitos (e.g., olhar conjunto e exposição repetida e consistente a relações palavras-objetos/ações) se relacionam com a aquisição de repertórios de compreensão e produção lingüísticas a partir dos 8 meses de vida; e 2) com novos participantes, procurando verificar a replicabilidade e generalidade dos dados obtidos até o momento.

\section{REFERÊNCIAS}

Brino, A. L. F., \& Souza, C. B. A. (2005). Comportamento verbal: Uma análise da abordagem skinneriana e das extensões explicativas de Stemmer, Hayes e Sidman. Interação em Psicologia, 9, 253-262.

Butterworth, G., \& Grover, L. (1988). The origins of referential communication in human infancy. Em L. Weiskrantz (Org.), Thought without language (p. 5-24). New York: Oxford University Press.

Cavalcante, C. T. F., \& Souza, C. B. A. (2006). Variáveis paramétricas na aquisição de pré-requisitos da linguagem: Análise longitudinal da interação criança-acompanhante. Relatório de pesquisa não publicado, Universidade Federal do Pará, Belém. 
Correa, L. M. S. (1999). Aquisição da linguagem: Uma retrospectiva dos últimos trinta anos. Delta, 15, 339-383.

Lowenkron, B. (1998). Some logical functions of joint control. Journal of the Experimental Analysis of Behavior, 69, 327-354.

Lyra, M. C. D. P. (2000) Desenvolvimento de um sistema de relações historicamente construído: Contribuições da comunicação no início da vida. Psicologia: Reflexão e Crítica, 13, 257-268.

Moerk, E. L. (1996). Input and learning processes in first language acquisition. Em H. W. Reese (Org.), Advances in child development and behavior: Vol. 26 (p. 181-228). New York: Academic Press.

Pullum, G. K., \& Scholz, B. C. (2002). Empirical assessment of stimulus poverty arguments. The Linguistic Review, 19, 9-50.

Ribes, E., \& Quintana, C. (2003). Mother-child linguistic interactions and behavioral development: A multidimensional observational. The Behavior Analyst Today, 3, 442-454.

Seidl de Moura, M. L., Ribas, A. F. P., Seabra, K. C., Pessôa, L. F., Ribas, R. C., \& Nogueira, S. E. (2004). Interações iniciais mãe-bebê. Psicologia Reflexão e Crítica, 17, 295-302.

Skinner, B. F. (1992). Verbal behavior. Acton, MA: Copley Publishing Group. (Original publicado em 1957)

Souza, C. B. A. (2001). Adquisición de competencias lingüísticas: Una propuesta de análisis funcional. Tese de doutorado nãopublicada, Centro de Estudios e Investigaciones em Comportamiento, Universidad de Guadalajara, Jalisco, México.

Souza, C. B. A. (2003). Uma proposta de análise funcional da aquisição da linguagem: Resultados iniciais. Interação em Psicologia, 7, 83-91.

Souza, C. B. A., \& Affonso, L. R. (2007). Pré-requisitos da linguagem: Padrões comportamentais na interação criançaacompanhante. Interação em Psicologia, 11, 43-54.

Stemmer, N. (1992). The behavior of the listener, generic extensions, and the communicative adequacy of verbal behavior. The Analysis of Verbal Behavior, 10, 69-80.

Stemmer, N. (1996). Listener behavior and ostensive learning. Journal of the Experimental Analysis of Behavior, 65, 247-249.
Tomasello, M. (2003). Constructing a language: A used-based theory of language acquisition. Cambrigde, MA: Harvard University Press.

Vieira, J. R., Brasil, S. E. R., \& Souza, C. B. A. (2005). Processos e procedimentos comportamentais na aquisição de prérequisitos da linguagem: Um estudo longitudinal da interação criança-acompanhante [Resumo]. Em Programa de Pósgraduação em Teoria e Pesquisa do Comportamento (Org.), Programa e resumos da VIII Semana Científica do Laboratório de Psicologia (p. 15). Belém, PA: UFPA.

Whitehurst, G. J. (1996). On the origins of misguided theories of naming and other symbolic behavior. Journal of the Experimental Analysis of Behavior, 65, 255-259.

Whitehurst, G. J., \& DeBaryshe, B. D. (1989). Observational learning and language acquisition. Em G. E. Speidel \& K. E. Nelson (Orgs.), The many faces of imitation in language learning (p. 251-276). New York: Springer-Verlag.

Whitehurst, G. J., \& Kedesdy, J. (1981, agosto). An associative theory of early vocabulary acquisition. Trabalho apresentado na $89^{\text {th }}$ Annual Convention of the American Psychological Association.

Whitehurst, G. J., Kedesdy, J., \& White, T. G. (1982). A functional analysis of meaning. Em S. A. Kuczaj II (Org.), Language development: Vol. 1. Syntax and semantics (p. 397-427). Hillsdale, NJ: Erlbaum.

Whitehurst, G. J., \& Valdez-Menchaca, M. C. (1988). What is the role of reinforcement in early language acquisition. Child Development, 59, 430-440.

Wittgenstein, L. (1953). Philosophical Investigations. New York: Macmillan.

Zamberlan, M. A. T. (2002). Interação mãe-criança: Enfoques teóricos e implicações decorrentes de estudos empíricos. Estudos de Psicologia (Natal), 7, 399-406.

\section{Sobre os autores:}

Recebido: 22/06/2006 Revisado: 06/05/2007 Aceito: 09/06/2007

Carlos Barbosa Alves de Souza: Professor Adjunto 3 do Departamento de Psicologia Experimental da UFPA e do Programa de Pósgraduação em Teoria e Pesquisa do Comportamento da UFPA.

Sirleany de Souza Pontes: Bolsista de Iniciação Científica do CNPq.

Endereço para correspondência: Rod. Arthur Bernardes, 1.650 - Cond. Alto de Pinheiros - Pratinha - CEP 66825-000 - Belém, PA. Endereço eletrônico: carlos.souza@pesquisador.cnpq.br 